\title{
A SYSTEMATIC REVIEW ON THE PREVALENCE OF MENTALLY CHALLENGED ADOLESCENTS IN INDIA AND THE EFFICACY OF DIETARY SUPPLEMENTS WITH HERBS ON COGNITIVE FUNCTION
}

\author{
The Research Centre of Home Science, Fatima College (Autonomous), Madurai, India \\ Received - July 18, 2020; Revision - September 17, 2020; Accepted - October 29, 2020 \\ Available Online - March 25, 2021 \\ DOI: http://dx.doi.org/10.18006/2021.9(Spl-1-GCSGD_2020).S23.S29
}

Manjula J, Karthiga K*

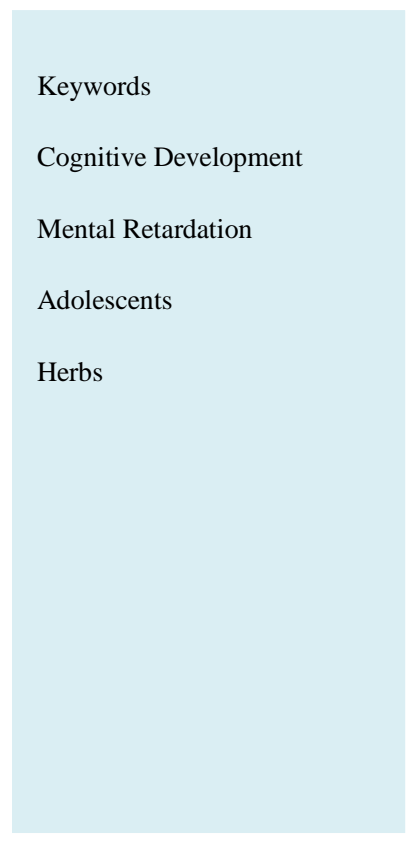

\begin{abstract}
Health is the state of well-being in physical, social, spiritual, and mental health. Apart from physical health, mental health is of prime importance. The brain is one of the most complex organs in the body. The brain has multiple tasking abilities like learn, play, concentrate, remember and it helps in sustaining a clear mind. Brain comprises around 60\% fat with omega 3 fatty acid and Docosahexaenoic acid, these two supports the normal neuronal membranes. The modern diet lacking in omega 3 and DHA may harm cognitive development. In the world, India stands second place with a population of 135.26 crores. India comprises one fifth of the adolescent population that is around $27.05 \%$ of the total population. According to the American Association on Intellectual and Developmental Disabilities, "Mental retardation is a disability characterized by significant limitations both in intellectual functioning and in adaptive behaviour. Mental health in adolescents is neglected and it increased morbidity and mortality during recent years. Cognitive development in adolescence occurs in three main areas. The three areas are advanced reasoning skills, abstract thinking, and formal operational thinking. The psychiatric disorders in adolescents begin before the age of 14 and nearly $50 \%$ of adolescents are affected during this period. The remaining $20 \%$ of the adolescent's population are affected by predisposing or precipitating factor. Plants have been used as a medicine based on folk remedies and experience. Due to the immense potential of medicinal plants, the research work was planned to carry out on plant based medicine. Various nutraceuticals and pharmaceutical components have been derived from medicinal plants. Plants such as Centella asiatica, Bacopa monnieri, and various herbs are rich source of omega 3, Alpha-linolenic acid, Minerals and Vitamins which helps in cognitive development and work as memory enhancer in human being.
\end{abstract}

* Corresponding author

E-mail: arjun.maya1@gmail.com (Karthiga K)

Peer review under responsibility of Journal of Experimental Biology and Agricultural Sciences.

Production and Hosting by Horizon Publisher India [HPI] (http://www.horizonpublisherindia.in/).

All rights reserved.
All the articles published by Journal of Experimental Biology and Agricultural Sciencesare licensed under a Creative Commons Attribution-NonCommercial 4.0 International License Based on a work at www.jebas.org.

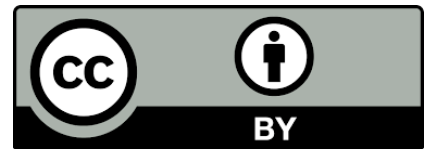




\section{Introduction}

India is the second-largest population in the world and comprises the largest population of adolescents with $27.05 \%$ (Plecher, 2020). Adolescents are individuals between $10-19$ years and they undergo an intervening stage with characteristic changes in social, emotional, cognitive, sexual, and physical development. Many problems in adulthood have their roots in adolescence. Adolescent health needs can be categorized into three types i.e. physical, psychological, and social. The major health issue faced by adolescents in recent years is mental illness. The integral part of health is mental wellness (Sivagurunathan et al., 2015).

The main challenge in mental illness is always a fight between one's change in mind and society. Adolescents will experience different and variety of emotional changes. The prevalence rate of mentally challenged adolescents in India ranges from $10.8 \%$ 13.9\% (Hossain \& Purohit, 2019). In developing countries like India, there is less awareness about mental illness. In many areas, they are not even identified and managed. Our ancestors have been in close contact with the nature and environment. They have used the plants as the ingredients of food and also as a curative medicine too. Almost, in all cultures, plants have been used as medicinal resources. In the world, medicinal plants and their parts were used as drugs.
These plant and plant parts have many active components. These components act as a curative component for a particular disease (Kia et al., 2017). World Health Organization estimated that $80 \%$ of people worldwide depend on herbal medicines for their primary health issues (Tagboto \& Townson, 2001). Cognitive development is the framework of remembrance, problem solving skills, decision making from childhood to adulthood (Sternberg, 2003). The present review is focusing on the prevalence of mentally challenged adolescents in India and also on the medicinal herbs that help in cognitive development and used as a memory enhancer.

\section{Adolescence - A Dynamic Period}

The most rapid phase of human development is adolescent. Biological maturity precedes psycho-social maturity. Adolescence is the period of transition between childhood and adulthood. The adolescent does not undergo only physical changes but they also experience cognitive, social/emotional, interpersonal changes as well. When they develop, adolescents are predisposed by environmental factors such as parents, peers, community, culture, religion, school, world events, and media. Every person differs in personality, interest, and other issues in an early, middle, late adolescence stage (AACAP, 2003).

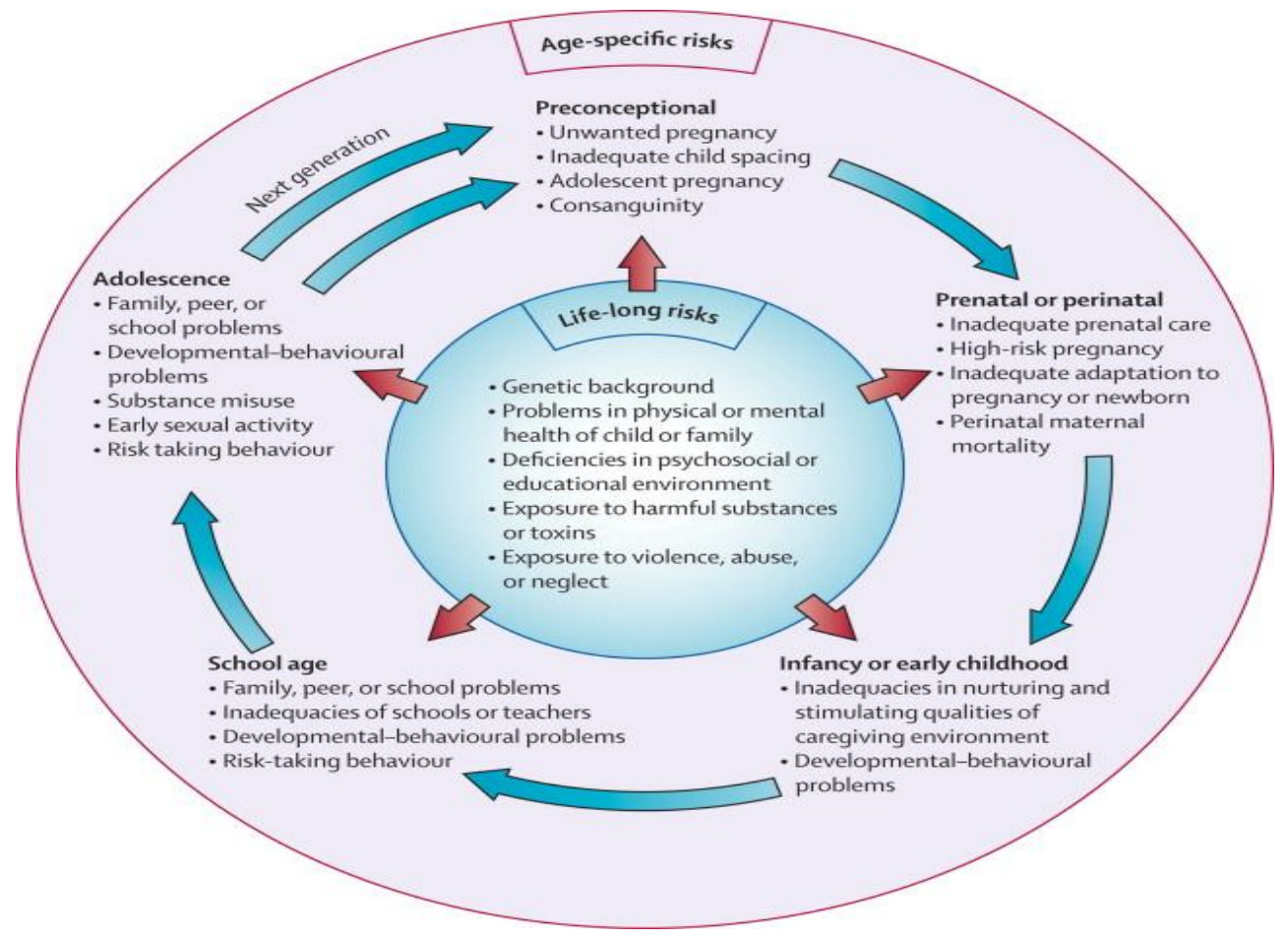

Figure 1 Child And Adolescent Mental Health Worldwide: Evidence For Action, 2011 (Christian et al., 2011) 
Cognitive development is the attainments of a more fully conscious, self-directed, and self-regulating mind (Keating, 2004).

This is achieved principally through the assembly of an advanced 'executive suite' of capabilities (Donald, 2001), rather than through specific advancement in any one of the constituent elements. First, adolescents develop more advanced reasoning skills and deeper moral thinking. Second, adolescents move from thinking to reasoning. Third, the formal operational thinking characteristic of adolescence enables adolescents to think about thinking or meta-cognition (Renata, 2013).

\section{Adolescent Population in India}

Worldwide, Asia is the home for more than half of the adolescent population. In South Asia, the number of the adolescent is 350 million while this number was reported 300million in East Asia and the Pacific (United Nations, Department of Economic and Social Affairs, 2019).
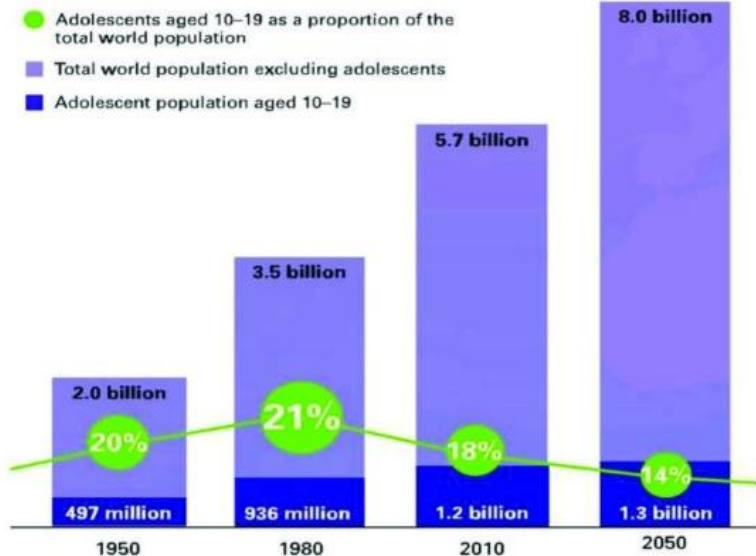

Figure 2 Proportions of Adolescents and World Population (Source: Progress for Children; A Report Card on Adolescents. UNICEF)

Table 1 Five Top Ranks of Adolescent Sex Ratio

\begin{tabular}{|cc|} 
Top five states/ UTs2011 & $\begin{array}{c}\text { Adolescent sex ratio } \\
\text { (Females per 1000 } \\
\text { males) }\end{array}$ \\
\hline Lakshadweep & $1053: 1000$ \\
\hline Arunachal Pradesh & $983: 1000$ \\
\hline Odisha & $981: 1000$ \\
\hline Meghalaya & $979: 1000$ \\
\hline Chhattisgarh & $972: 1000$ \\
\hline
\end{tabular}

Source: A Profile of Adolescents and Youth in India, UNFPA, 2011
India, the second largest populous country has a total population of more than 1.21 billion and constitutes an adolescent population of 243 million (Youth in India 2017). The following list was top five states/Union Territories, the population of Indian adolescent collected in census 2011 .

\section{Prevalence of Mentally Challenged Adolescent in India}

Worldwide the depressive disorder starts at an early age and with the prevalence rate of mental illness. Among children and adolescent the prevalence rate of mental disorders ranges between $1 \%$ and $51 \%$ (Sandal et al., 2017). The prevalence rate was from $10 \%$ to $20 \%$ in adolescent between the age group 14 and 19 years (Kessler et al., 2007). Many mental health disorders like depression, anxiety and further more are present during adolescent. $20 \%$ of adolescent have an identifiable and curable mental health disorder. As per the National Mental Health Survey of India (2015-2016), the prevalence of psychiatric disorders among adolescents (13-17 years) is reported around $7.3 \%$.

\section{Natural Memory Boosters}

From 16th century herbals were used to treat age related cognitive disorders. Many plants have been used to treat cognitive and other disorders. More than 150 plant species have been used in various preparations and mixtures (Desousa, 2014). The recent trend is using herbal medicines through which the overall condition of an individual, body, and mind equilibrium can be achieved. The herb which develops cognition is called medhya herbs (www.holistic herb.com, 2008). In Ayurveda, the mind power is categorized into three types called triads. The first one is acquisition power which is used to grasp a new thing or to understand or analyze it. The second is the power of retention which will retain the things what has been understood and the last one is recollecting power which helps in retrieving information that is stored and leaves in long term memory (Rathee et al., 2008). The nootropic herbs acts on the brain and the constituents or components isolated from this are named smart drugs. These drugs increase the blood circulation in the brain and enhance memory (Sahelian, 2000). Many plants have the capacity to recuperation from cognitive disorder and other memory related disorders. Bacopa moniera (Bramhi), Ginkgo biloba, Shankhpushpi, etc. and some other types of herbs can enhance cognition potential (Nabi,2014). The following is a list of effective herbs used in memory enhancement all over the world.

\subsection{Ginkgo biloba}

Ginkgo biloba belongs to the family Ginkgoaceae. Gingko leafs are used as a edible one. Ginkgo biloba eliminates the free radical and there by improve the behavioural adaptation for memoryenhancement. The active components present in it are 
flavonoids such as quercetin, kaempferol and isorhamnetin. Minor flavonoids

proanthocyanidins, catechins, flavones and terpene ginkgolides (Birks et al., 2002).

\subsection{Centella asiatica}

Centella asiatica, belongs to the family Umbelliferae. It is commonly known as Centella asiatica, commonly known as Mandookaparni (Kokate., 2005). It is an Indian herb and it is also used as spice. The main purpose for its usage is, it helps in memory boosting, increase concentration, intelligence quotient in mentally retarded children (Sekar, 1996).

\subsection{Bacopa monnieri}

Bacopa monnieri belongs to the family plantaginaceae. It is used as memory and attention enhancement. It is given to infants for boosting the memory power. The active constituents present in the herbs are alkaloids and saponins. The major constituents are the steroidal saponins, Bacosides A and B. Thesaponins, baco side A and $B$ are the active principles used for the enhancement ofcognitive function (Russo et al., 2005).

\subsection{Acorus calamus}

Acorus calamus belongs to the family Acoraceae. It is used as brain tonic. Stems, leaves and roots are used in ayurvedic medicine. It is helpful in treating brain tissue detoxification, concentration, thinking process (Chaturvedi et al.,2017). The constituents are alkaloids, flavonoids, gums, pectins, mucilage, phenols, quinone, saponins, sugars, tannins, and triterpenes. The active constituents includeflavonoids, lectins, phenols, and saponins.

\subsection{Tinospora cordifolia}

Tinospora cordifolia belongs to the family Menispermacaceae. It is used for treating Alzheimer's disease, improve cerebral ischaemia, regulation of cytokines, depression and attention deficit Hyperactivity disorder. They contain active constituents such as alkaloids, steroids, polysaccharides, glycosides (Joshi, 2013). The benefits of these herbs are enormous and it helps the human society. Hippocrates states "Nature is the best Physician" so it can treat each and every illness. The extract from leaves, roots and stem from these herbs have impending use in memory enhancement.

\section{Efficacy of Herbal Dietary Supplements on Cognitive Function:}

A dietary supplement is defined as "a manufactured or commercially available products which added purposely to food in an intention to achieve the targeted benefit" (Maughan et al.,
2018). Mostly dietary supplements include specific components such as multivitamins, minerals, proteins, hormones, plant derived compounds, combination products, and non-categorical supplements like animal or synthetically derived substances. These dietary supplements are available in many forms like powders, capsules, tablets, energy drinks, and even cereals (Knapik et al., 2016). The global dietary supplements market estimated that in 2020 the market value will rise to 220.3 billion in USD (Zion Market Research, 2016).

Centellaasiatica is used as a memory enhancer. In a study conducted by AppaRao et al. (1977), thirty children were selected from the age of 7-18. The test was based on the general mental ability of mentally retarded children. Stanford Binet Test was performed for intelligence testing before the study and their urine samples were also tested for amino acid urea and other inborn errors.

Thirty children were separated into two groups. One group received $0.5 \mathrm{~g}$ of Centellaasiatica tablet and the placebo received tablets made of starch. The final result was that the children who consumed Centellaasiatica tablet showed improvement in intelligence and general adaptive behaviour of the mentally retarded children.

Further, Dev et al. (2009) conducted a comparative study on the Cognitive effects of $C$. Asiatica in Healthy Middle Age Female and Male Volunteers with the range of 35-50 years. 22 females and 19 males were selected as participants and they were divided into two groups. Woodcock-Johnson Cognitive Abilities test III was performed before the trial.

The study concluded that $C$. asiatica has the potential to reduce the age related decline in cognitive function in healthy middle age and elderly adults. The placebo received colour coated pills and the other group received $3-4 \mathrm{~g}$ of $C$. asiatica (according to body weight).

Similarly, Bacopamonnieri is used for cognition and memory enhancement. In a study conducted by Ramakrishnan et al. (2017) the efficacy of Brahmi was tested on Cardio Vascular Accident patients and cerebral palsy patients with behavioral problems. The groups were divided into two, in one group 15C.V.A patients werethere and inanother group 15 cerebral palsychildren. They were given Brahmi tablets and were instructed to take the pills for 30 days.

Psychological well-being scale, bartheles index, FIM scale, the positive and negative schedule is used before and after the trial. The result revealed that there was an improvement in the cognitive function in CVA and Cerebral Palsy patients. On comparison, 


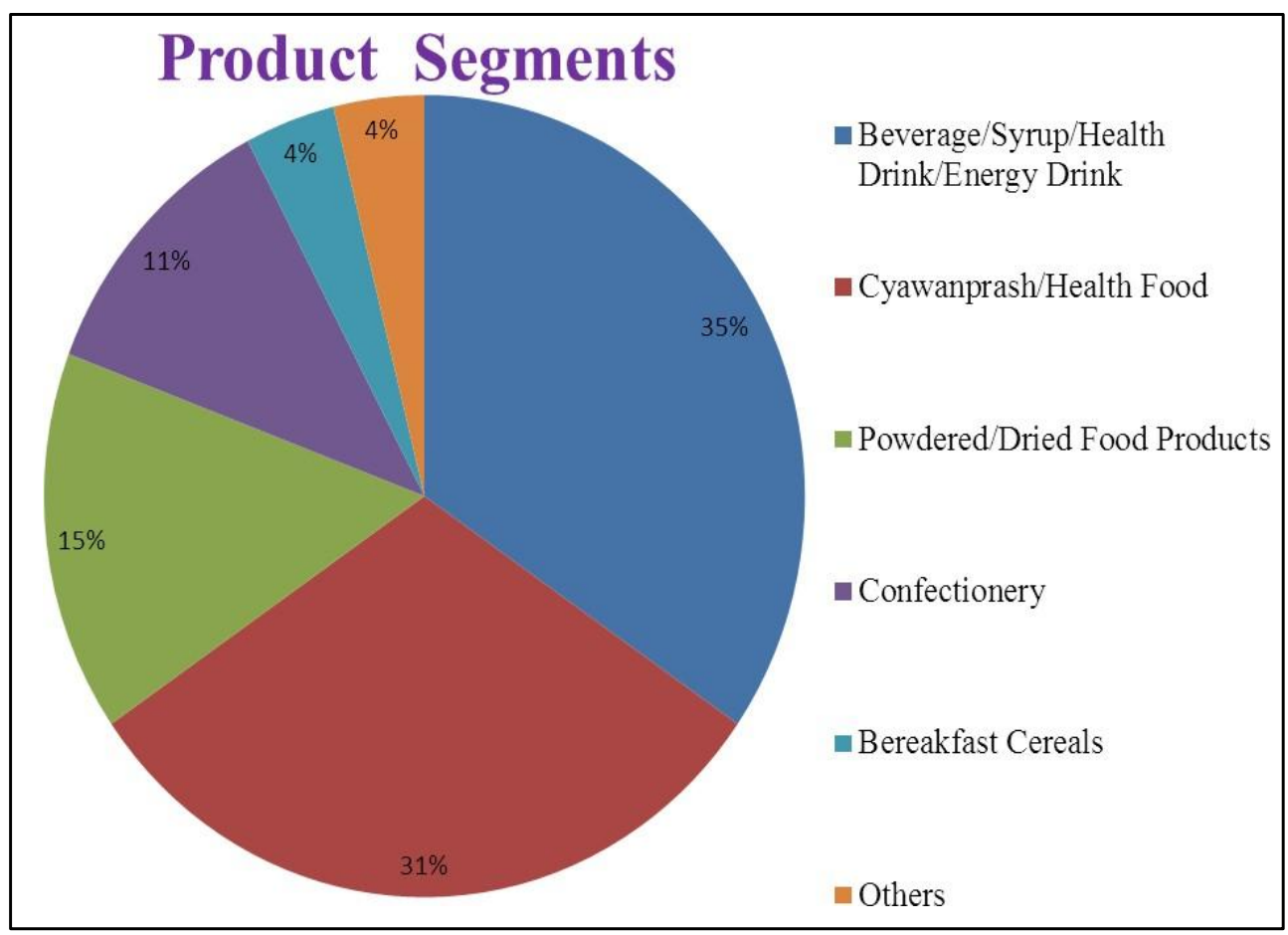

Figure 3 Sector wise Segregation of Products containing Brahmi as a functional Food ingredient (Source: Global New Products Database, 2017)

cerebral palsy patients benefited more.According to previous researches, the population below 18 years is 447 million in India. Out of 447 million 29 million suffer from any one of the psychiatric problems. In India, the development of hildren and adolescent psychiatry is very slow and it is difficult to handle the huge problem (Aggarwal, 2003).

India with an abundant population of adolescent has a rising number of mentally challenged problems.

\section{Conclusion}

The lifestyle modification like dietary habits, lack of exercise, anxiety, stress, and emotional all leads to psychological problems. The main problem in adolescent is to develop both physical and psychological. These transitional changes lead to stress and in many cases, it leads to serious mental health conditions emerge during adolescence. The psychological tablet leads to increase in weight, hormonal changes, loneliness, and many other things. The plant sources are one which is beneficial to health, and it is nonhazardous when consumed. The plant materials contain a lot of primary, secondary, and many bioactive molecules. The main role of certain herbs helps in improving cognition, memory enhancement. Herbs are healing of the nation, so future research studies should be based on the molecular basis of herbs in humans.

\section{Acknowledgments}

I am very glad to express my heartfelt thanks to Rev. Dr.Sr. M. rancisca Flora, Secretary, and Rev. Dr.Sr.G. Celine SahayaMary, Principal, Fatima College, Madurai for their blessings during the entire work.I express my grateful thanks to Dr.Vasantha Esther Rani, Head.

The Research Centre of Home Science, Fatima College, Madurai for her best wishes, support, valuable advice, and encouragement. I am privileged to express my deep sense of gratitude and respect to my Project guide Dr. K. Karthiga, M.Sc., Ph.D., NETAssistant Professor, The Research Centre of Home Science for her patience, motivation, enthusiasm, and immense knowledge. Her guidance helped me in all the time. I could not have imagined having a better advisor and mentor for my Present work.

\section{Conflict of interest}

The authors declare that they have no conflict of interest.

\section{References}

ACAP (2003) American Academy of Child and Adolescent Psychiatry. 
Aggarwal SP (2003) Mental Health: An Indian Perspective 19462003. Medical Journal Armed Forces India 61: 205.

Appa Rao MVR, Srinivasan K, Koteswara Rao T (1977) The Effect of Centellaasiatica on the General Mental Ability of Mentally Retarded Children. Indian Journal of Psychiatry 4: 5459.

Birks J, Grimley JE, Van MD (2002) Ginkgo biloba for Cognitive Impairment and Dementia (Cochrane Review). In: The Cochrane Library, Issue 4.

Chaturvedi M, Chaturvedi AK (2017) Acorus calamus: A Divine Drug for the Human being. Imperial Journal of Interdisciplinary Research 3: 1499-503.

Christian K, Baker-Henningham H, Belfer M, Conti G, Ertem I, et al. (2011) Child and Adolescent Mental Health Worldwide: Evidence for Action. Global Mental Health 378: 1-11.

Desousa A (2014) Herbal Medications to Enhance Cognition and Cognitive Ability, Department of Psychiatry, Lokmanya Tilak Municipal Medical College, Mumbai.

Dev RDO, Mohamed S, Hambali Z, Samah BA (2009) Comparison on Cognitive Effects of Centella asiatica in Healthy Middle Age Female and Male Volunteers. European Journal of Scientific Research 31: 553-565.

Dhingra D, Goyal PK (2008) Evidences for involvement of Monoaminergic and GABAergic system in Antidepressanst like Activity of Tinosporacordifolia in mice. Indian Journal of Pharmaceutical Sciences 40: 761-767.

Donald M (2011) A Mind So Rare: The Evolution of Human Consciousness, Norton.

Hossain MM, Purohit N (2019) Improving Child and Adolescent Mental Health in India: Status, Services, Policies and Way Forward. Indian Journal of Psychiatry 61: 415-419.

Keating DP (2004) Handbook of Adolescent Psychology, John Wiley and Sons Inc, Washington, Pp. 45-84.

Kessler RC, Angermeyer M, Anthony JC (2007) Lifetime prevalence and age-of-onset distributions of mental disorders in the World Health Organization's World Mental Health Survey Initiative. World Psychiatry 6: 168-76.

Kia FJ, Lorigooini Z, Khoei HA (2017) Medicinal Plants: Past History and Future Perspective. Journal of Herbmed Pharmacology 1: $1-7$.

Knapik JJ, Trone DW, Austin KG, Steelman RA, Farina EK, Lieberman HR (2016) Prevalence, Adverse Events, and Factors Associated with Dietary Supplement and Nutritional Supplement Use by US Navy and Marine Corps Personnel. Journal of Academy of Nutrition and Dietetics 116: 1423-1442.
Kokate CK, Purohit AP, Gokhale SB (2005) A Text Book of Pharmacognosy", Edn.-XIII, Published by Niraliprakashan, Pune , Pp: 91, 219,221,234,511,518.

Massey AJ (1999) Effectiveness of ginkgo biloba in memory disorders. Journal of Pharmacy Practice12: 217-224.

Maughan RJ, Burke LM, Dvorak J, Larson-Meyer DE, Peeling P, et al. (2018) IOC consensus statement: dietary supplements and the high-performance athlete. British Journal of Sports Medicine 52: 439-455.

Nabi NU (2014) Natural Remedies for Improving Learning and Memory-Review. International Journal of Pharmaceutical and Phytopharmacological Research 3: 161-165.

Plecher H (2019) Distribution of the workforce across economic sectors in the United States.

Pranav JC (2013) A review on natural memory enhancers (Nootropics). Unique Journal of Engineering and Advanced Sciences 1: 8-18.

Ramakrishnan KS, Sathya, EktaSajgotra (2017) Efficacy of Brahmi in Cognitive Function - A Comparison between Cerebral Palsy Children and C.V.A Patients. International Journal of Innovative Research in Science, Engineering and Technology 6: $6945-6952$.

Rathee P, Chaudhary H, Rathee S, Rathee D (2008) Review Article Natural Memory Boosters. Pharmacognosy Reviews 2: 249-256.

Renata AS (2013) Adolescent Psychosocial, Social, and Cognitive Development. Journal of the American Academy of Paediatrics 34: 354-359.

Russo A, Borelli F (2005) Bacopa monniera, a reputed nootropic plant: An overview. Phytomedicine 12: 305-317.

Sahelian (2000) Mind boosters: a guide to natural supplements that enhance your mind, memory, and mood, St. Martin's Press, New York, pp. 43-52.

Sandal RK, Goel NK, Sharma MK, Bakshi RK, Singh N, Kumar D (2017) Prevalence of depression, anxiety and stress among school going adolescent in Chandigarh. Journal of Family Medicine and Primary Care 6: 405-410.

Sekar P (1996) Vedic clues to memory enhancer. The Hindu, March 21, 1996.

Sivagurunathan C, Umadevi R, Rama R, Gopalakrishnan S (2015) Adolescent Health: Present Status and Its Related Programmes in India. Are We in the Right Direction? Journal of Clinical and Diagnostic Research 9: 1-6. 
Sternberg RJ(2003) Wisdom, intelligence, and creativity synthesized. Cambridge University Press.

Tagboto S, Townson S (2001) Antiparasitic properties of medicinal plants and other naturally occurring products. Advances in Parasitology 50:199-295. doi: 10.1016/s0065-308x(01)50032-9.

Tiwari S, Singha S, Patwardhan K, Gehlot S, Gambhira IS (2008) Effect of Centellaasiatica on Mild Cognitive Impairment (mci) and other Common Age-related Clinical Problems. Digest Journal of Nanomaterials and Biostructures 3: 215 - 220.

UNFPA (2011) A Profile of Adolescents and Youth in India,
United Nations, Department of Economic and Social Affairs, (2019).

Williamson ME (2002) Major Herbs of Ayurveda. Churchill Livingston, London, UK. World Health Organization (2004).

Youth in India (2017) Youth in India, Central Statistics Office Ministry of Statistics and Programme Implementation Government of India (Social Statistics Division, (2017).

Zion Market Research (2016) Dietary supplements market by ingredients (Botanicals, Vitamins, Minerals, Amino Acids, Enzymes) for additional supplements, medicinal supplements and sports nutrition applications - Global industry perspective, Comprehensive analysis and forecast, (2016-2022). 